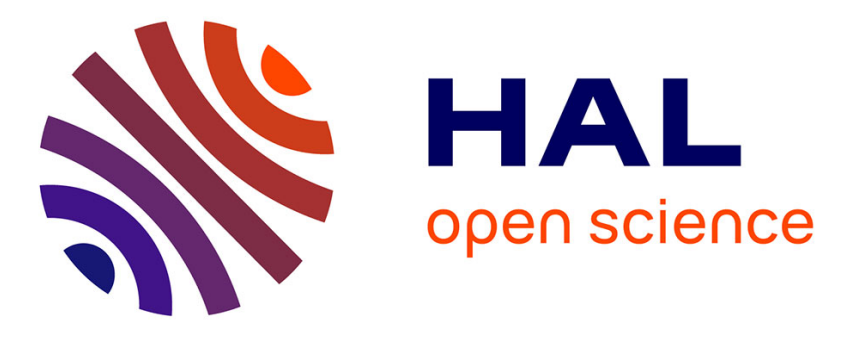

\title{
Microfluidic flow-through reactor and 3D Raman imaging for in situ assessment of mineral reactivity in porous and fractured porous media
}

Jenna Poonoosamy, Cyprien Soulaine, Alina Burmeister, Guido Deissmann, Dirk Bosbach, Sophie Roman

\section{To cite this version:}

Jenna Poonoosamy, Cyprien Soulaine, Alina Burmeister, Guido Deissmann, Dirk Bosbach, et al.. Microfluidic flow-through reactor and 3D Raman imaging for in situ assessment of mineral reactivity in porous and fractured porous media. Lab on a Chip, 2020, 20 (14), pp.2562-2571. 10.1039/D0LC00360C . insu-02906035

\section{HAL Id: insu-02906035}

\section{https://hal-insu.archives-ouvertes.fr/insu-02906035}

Submitted on 13 Nov 2020

HAL is a multi-disciplinary open access archive for the deposit and dissemination of scientific research documents, whether they are published or not. The documents may come from teaching and research institutions in France or abroad, or from public or private research centers.
L'archive ouverte pluridisciplinaire HAL, est destinée au dépôt et à la diffusion de documents scientifiques de niveau recherche, publiés ou non, émanant des établissements d'enseignement et de recherche français ou étrangers, des laboratoires publics ou privés. 



Devices and applications at the micro- and nanoscale

\section{Accepted Manuscript}

This article can be cited before page numbers have been issued, to do this please use: J. Poonoosamy,

C. Soulaine, A. Burmeister, G. Deissmann, D. Bosbach and S. Roman, Lab Chip, 2020, DOI:

\subsection{9/DOLC00360C.}
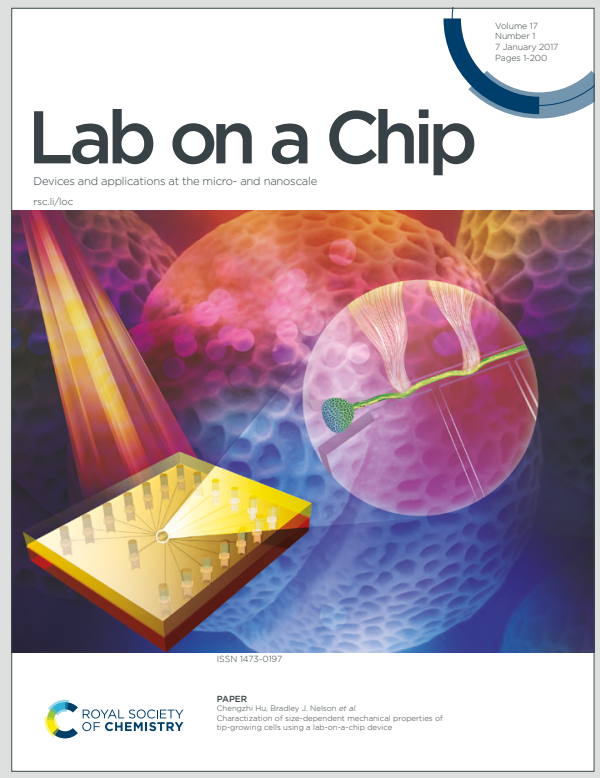

This is an Accepted Manuscript, which has been through the Royal Society of Chemistry peer review process and has been accepted for publication.

Accepted Manuscripts are published online shortly after acceptance, before technical editing, formatting and proof reading. Using this free service, authors can make their results available to the community, in citable form, before we publish the edited article. We will replace this Accepted Manuscript with the edited and formatted Advance Article as soon as it is available.

You can find more information about Accepted Manuscripts in the Information for Authors.

Please note that technical editing may introduce minor changes to the text and/or graphics, which may alter content. The journal's standard Terms \& Conditions and the Ethical guidelines still apply. In no event shall the Royal Society of Chemistry be held responsible for any errors or omissions in this Accepted Manuscript or any consequences arising from the use of any information it contains. 


\title{
Journal Name
}

\section{ARTICLE TYPE}

\section{Microfluidic flow-through reactor and 3D Raman imaging for in situ assessment of mineral reactivity in porous and fractured porous media $^{\dagger}$}

\author{
Jenna Poonoosamy, ${ }^{* a}$ Cyprien Soulaine, ${ }^{b}$ Alina Burmeister, ${ }^{c}$ Guido Deissmann, ${ }^{a}$ Dirk \\ Bosbach $^{a}$ and Sophie Roman ${ }^{b}$
}

\begin{abstract}
Received Date
\end{abstract}
Accepted Date

DOI: $00.0000 / x x x x x x x x x x$

\begin{abstract}
An in-depth understanding of dissolution and precipitation of minerals in porous and fractured porous media and the complex feedback on the transport of fluids is essential for various subsurface applications. In this context, we developed a novel non-destructive "lab-on-chip" approach for quantitative in situ assessments of mineralogical changes in porous media. Our experimental approach involves a microfluidic flow-through reactor of reactive homogeneous and heterogeneous (fractured) porous media coupled with high-resolution imaging. Here, the reactive medium consists of compacted celestine grains seeded in a reservoir within the microfluidic chip. This medium reacts with a barium chloride solution injected into the microreactor at a constant flow rate, leading to the dissolution of celestine and growth of barite. Various seeding processes of the mineral grains allow the creation of homogeneous reactive porous media or the introduction of large heterogeneities such as fractures. Hence, our approach enables high-resolution investigations of reactive transport in fractured porous media. The use of confocal Raman spectroscopic techniques enables the spatio-temporal visualization of the mineral transformation at the pore-scale in two- and three-dimensions. Moreover, advanced porescale modelling correlates the hydrological heterogeneities to the geochemical observations in the micro-reactor, which explains the observed discrepancies between homogeneous and heterogeneous reactive media. Eventually, the proposed methodology can be applied to other chemical systems to provide new insights into hydro-geochemical coupling in porous and fractured porous media as well as high-fidelity datasets to benchmark reactive transport codes that are currently under development.
\end{abstract}

\section{Introduction}

Reactive transport modelling 112 , is a versatile tool in predicting or assessing mineralogical changes due to reactive fluids in space and time for various subsurface applications including shale gas production using hydraulic fracturing ("fracking"), $\mathrm{CO}_{2}$ sequestration, geothermal energy extraction, the underground repositories for nuclear waste, or environmental remediation ${ }^{3 / 4}$. Because of its widespread applications, recent studies have been dedicated to test the underlying concepts of these numerical models using experimental benchmarks ${ }^{5}+9$ ? Discrepancies between nu-

\footnotetext{
${ }^{a}$ Address, Institute of Energy and Climate Research (IEK-6): Nuclear Waste Management and Reactor Safety, Forschungszentrum Jülich GmbH, 52425 Jülich, Germany. Tel: +49 2461 61-6468; E-mail: j.poonoosamy@fz-juelich.de

${ }^{b}$ Earth Sciences Institute of Orléans, Univ. Orléans, CNRS, BRGM, Orléans, France

${ }^{c}$ Institute of Bio- and Geosciences (IBG-1): Biotechnology, Forschungszentrum Jülich GmbH, 52425 Jülich, Germany.

$\dagger$ Electronic Supplementary Information (ESI) available: [details of any supplementary information available should be included here]. See DOI: 00.0000/00000000.
}

merical models and experimental observations were noted and mainly explained by the fact that reactive transport operates at the continuum-scale (averaged properties of the porous media, e.g. porosity, permeability, effective surface area) and considers upscaled parameters ${ }^{10111}$, while pore-scale features (e.g. surface roughness of minerals ${ }^{12}$ ) influence the macroscopic behaviour (e.g. transport properties) of the system. These experiments suggest the need to understand the processes occurring at the pore-scale and to develop process-based predictive models and mathematical relationships that account for small-scale heterogeneities 13 .

In the last decades, there has been a growing interest to use pore-scale modelling in combination with experimental imaging/characterisation of porous media as tools to get a better understanding of coupled chemical and transport processes and to upscale the results to a macroscopic representation 2144]17. A live monitoring of chemical processes and hydraulic pathways can be performed using non invasive techniques such as magnetic res- 
onance imaging ${ }^{18}$, positron emission tomography 19 , or neutron imaging 20 . The spatial resolution, however, is often a limiting factor for these techniques. Alternatively, high resolution experimental images can be used. For example, Prasianakis et al.21 investigated the effect of pore size distribution on the nucleation of sulphates in porous media using scanning electron microscopy (SEM) images of the reacted porous media. Noiriel et al. ${ }^{22}$ and Molins et al. $\stackrel{23}{ }$ combined pore-scale modelling with X-ray microtomography imaging to assess calcite dissolution. These imaging techniques may nevertheless require specific facilities (e.g. Synchrotron) or can also be destructive without providing any information on the pore architecture or the spatial distribution of minerals of the original porous micro-structure (e.g. postexperimental characterization using SEM).

Another option that allows a direct visualization of flows, reactions and transport mechanisms at the pore-scale involves microfluidic devices coupled with optical microscopy techniques. Micromodels are two-dimensional representations of a porous medium in which the pore space is etched on a substrate by photolithography methods and then covered by a transparent material. The etched pattern may be of variable complexity ranging from single micro-channels of different shapes to patterns representative of natural porous media obtained from imaging of real rocks 24 . For now, microfluidic platforms are mainly based on glass, silicon or PDMS (a silicone elastomer) materials. However, transport and reaction dynamics depend also on rock surface chemistry. Recently, micromodels that include reacting minerals have emerged. They enable direct visualization of the fundamental fluid-mineral interactions at the pore-scale. For example, Song et al. $\frac{25}{}$ etched flow channels in a natural calcite crystal substrate that was bonded to a glass plate to investigate carbonate dissolution by an acidic brine. Soulaine et al. 15 investigated the complex feedback between hydrodynamics and surface chemistry using a single calcite crystal posted in a microchannel. Singh et al. 26 developed a real-rock/PDMS combined micromodel allowing them to investigate transport properties and multiphase flow in realtime.

In this paper we propose a new kind of micromodels based on a flow-through setup. It consists of a microfluidic reservoir filled with reacting crystals of controlled grain size and mineralogy with a reacting fluid flowing through it. The reservoir can contain either a homogeneous or a heterogeneous (fractured) porous medium. Our monitoring techniques include optical microscopy and Raman spectroscopy and allow in situ, non destructive and real-time monitoring of details on the chemical composition of the system at the grain-scale. The aim of this study is to assess the use of a new generation of microfluidic flow-through reactors in understanding mineral reactivity in porous and fractured porous media.

\section{Materials and methods}

In this section we describe our experimental setup and the measurement techniques that we developed to investigate mineral reactivity during micromodel experiments.

\section{Experimental concept}

The experimental setup consists of a micro-reactor connected to a pump and monitored by optical microscopy ( Fig. 11). We chose a well-controlled chemical system 13 , which is neither $\mathrm{pH}$ nor redox sensitive. The reactor includes a 'crystal reservoir' filled with celestine $\left(\mathrm{SrSO}_{4}\right)$ crystals. A barium chloride $\left(\mathrm{BaCl}_{2}\right)$ solution is injected in the reactor through the inlet at a constant flow rate. The injection of the $\mathrm{BaCl}_{2}$ solution triggers the dissolution of celestine and subsequently barite $\left(\mathrm{BaSO}_{4}\right)$ precipitation due to the difference in their solubility products $\left(K_{s p} \mathrm{BaSO}_{4}=10^{-9.97} \mathrm{~mol}^{2} \mathrm{~L}^{-2}\right.$ and $K_{s p} \mathrm{SrSO}_{4}=10^{-6.63} \mathrm{~mol}^{2} \mathrm{~L}^{-2}$ at $298.15 \mathrm{~K}$ and $1013 \mathrm{hPa}$, from Hummel et al.27).

The chemical reaction writes as follows,

$$
\mathrm{Ba}^{2+}{ }_{(a q)}+\mathrm{SrSO}_{4(s)} \rightarrow \mathrm{Sr}^{2+}{ }_{(a q)}+\mathrm{BaSO}_{4(s)} .
$$

\section{Micromodel}

The microfluidic reactor consists of a reservoir of $900 \mu \mathrm{m}$ length and $800 \mu \mathrm{m}$ width in which the reactive crystals are injected. The reservoir contains five supporting square pillars of $50 \mu \mathrm{m}$ length to enhance the mechanical stability. The reservoir is placed in between two sections (upstream and downstream, see Fig. 1) that constitute an artificial pore architecture made of cylindrical pillars of $100 \mu \mathrm{m}$ diameter and pore throats of $1 \mu \mathrm{m}$. The pore throat of $1 \mu \mathrm{m}$ enables the confinement of the crystals in the reservoir during the seeding process (see next section). Moreover, the upstream section (in the absence of heterogeneities in the distribution of crystals in the reservoir) enables an uniform flow of the solution as it reaches the reactive zone and the downstream section prevents that precipitates plug the outlet. The upstream and downstream sections are connected to the inlet and outlet respectively via channels of $2600 \mu \mathrm{m}$ length and $100 \mu \mathrm{m}$ width. The reservoir is connected to a crystal injection channel of $1900 \mu \mathrm{m}$ length and $300 \mu \mathrm{m}$ width. The crystal injection channel was made wide enough such that crystals do not get trapped but can be flushed freely during the seeding process. The depth of the microfluidic device is $10 \mu \mathrm{m}$, close to the size of the crystal which allows them to get stacked in the reservoir. The silicon wafer, produced by photolithography 28 , contains the positive relief of the micromodel and is used as a mold in the PDMS (Polydimethylsiloxane), Silicone Elastomer, Sylgrad) molding process. A cast of the micromodel is obtained by pouring transparent liquid PDMS onto the mold, baking it $\left(1 \mathrm{~h}, 65^{\circ} \mathrm{C}\right)$, and removing it from the wafer. Holes for the fluids interconnections are manually punched in the PDMS. Before bonding to the glass plate, the PDMS layer is cleaned with isopropanol, dried under nitrogen flow and treated with adhesive tape $\mathrm{e}^{29}$. An oxygen plasma treatment is applied to the PDMS and glass layers in order to activate their surface. Then, they are assembled and heated for 5 minutes at $80^{\circ} \mathrm{C}$ until they are securely bonded.

\section{Celestine seeding process}

The celestine crystals used in the experiments are obtained from naturally occurring celestine $\mathrm{SrSO}_{4}$ stones of $99.7 \%$ purity 7 . The stones were crushed and sieved to collect crystals of $<20 \mu \mathrm{m}$ grain 
a)

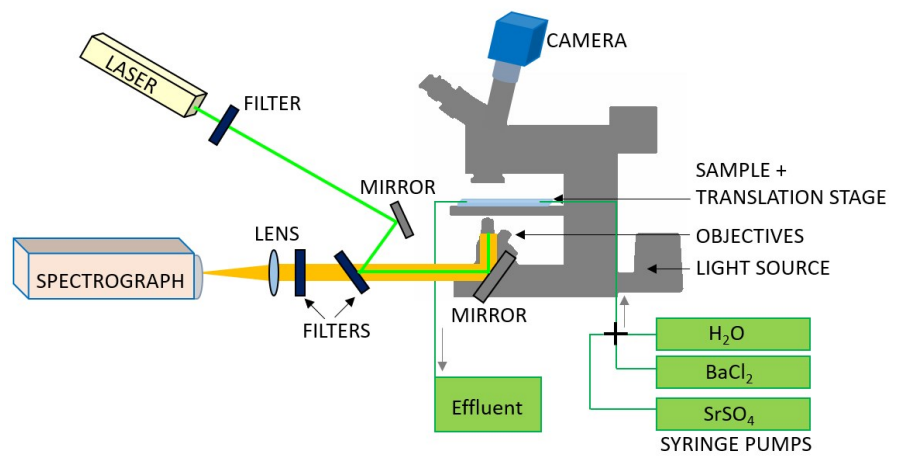

b)

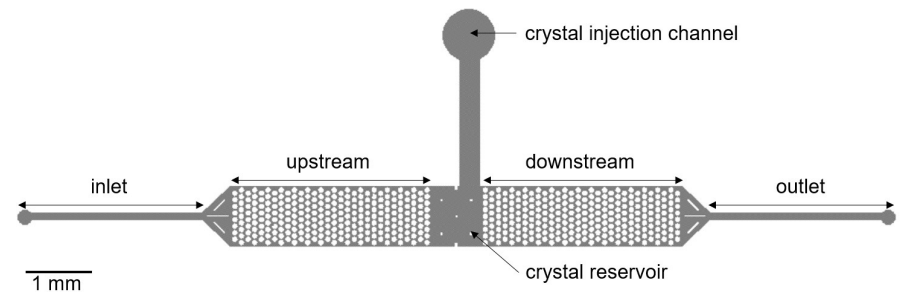

Fig. 1 a) Schematic of the experimental setup b) geometry of the micromodel, inlet and outlet channels are $0.10 \mathrm{~mm}$ wide and $2.50 \mathrm{~mm}$ long, upstream and downstream porous media are $0.90 \mathrm{~mm}$ wide and $3 \mathrm{~mm}$ long, the crystal reservoir is $0.90 \mathrm{~mm}$ wide and $0.80 \mathrm{~mm}$ long, the crystal injection channel is $0.3 \mathrm{~mm}$ wide and $1.9 \mathrm{~mm}$ long, the depth is $10 \mu \mathrm{m}$ everywhere.

size. This fraction of crystals was further segregated and crystals of grain size between $4 \mu \mathrm{m}$ and $9 \mu \mathrm{m}$ were isolated using sedimentation techniques (in isopropanol) in an Atterberg cylinder 30 . The celestine crystals were mixed in a saturated solution of strontium sulphate $\left(\mathrm{SrSO}_{4}\right)$ to constitute a seeding suspension. Prior to the injection of the seeding suspension, the microfluidic device was flushed with water to prevent gas bubbles being trapped in the system. The injection of the crystals using this technique can be used to generate a homogeneous compacted porous medium in the reservoir (Fig. 2a). By alternating the injection of the seeding suspension and the injection of a $\mathrm{SrSO}_{4}$ solution through the inlet, a heterogeneous (fractured) compacted porous medium can be obtained (Fig. 2p). The injection channel was mechanically closed using a stopper (Microfluidic luer lock stopper from Darwin Microfluidics, Delauney, France). A saturated $\mathrm{SrSO}_{4}$ solution was then injected at a constant flow rate of $1000 \mathrm{nLmin}^{-1}$ for 3 hours to stabilize the crystals in the reservoir, and later at $500 \mathrm{nLmin}^{-1}$ for 21 hours to ensure a steady-state condition, using a syringe pump (NeMeSYS, Cetoni GmbH, Germany). This step ensures that the crystals were well stabilized and less prone to colloidal movements in the reservoir. Two experiments were conducted, involving a homogeneous and a heterogeneous compacted porous medium, labelled A and B, respectively.

\section{Fluidics}

The inlet was connected to three dispensing syringes (water, a saturated solution of $\mathrm{SrSO}_{4}$ and a $1 \mathrm{mM} \mathrm{BaCl}_{2}$ solution) using a cross peek connector (052P-722, CS Chromatographie Ser- vice $\mathrm{GmbH}$, Langerwehe, Germany) and the outlet was linked to an effluent vessel. The micromodel was intially saturated with $\mathrm{SrSO}_{4}$ solution (see previous section). Then, water was injected at $500 \mathrm{nlmin}^{-1}$ for 30 minutes to prevent precipitation of barite in the upstream section. Finally, $\mathrm{BaCl}_{2}$ solution was injected into the microfluidic device at $500 \mathrm{nlmin}^{-1}$ for 60 hours.

\section{Imaging and Raman spectroscopy}

The microfluidic experiment was observed using an automated inverted microscope (Witec alpha300 Ri Inverted Confocal Raman Microscope which consists of an inverted Nikon Ti-2 U as base microscope) with $100 \times$ oil immersion objective of numerical aperture (NA) 1.25 , working distance $0.23 \mathrm{~mm}$ and cover glass correction for $0.17 \mathrm{~mm}$ from Nikon. The instrument is equipped with a Nd:YAG laser $(\lambda=532 \mathrm{~nm})$, and a thermoelectrically cooled CCD Camera and Ultra-High-Throughput Spectrometer UHTS300. The lateral and axial (depth) resolution of Raman measurements with the focus at the sample surface is usually estimated from the theoretical diffraction limit given by $d_{l} \approx \frac{1.22 \lambda}{N A}$ and $d_{a} \approx \frac{4 \lambda}{N A^{2}}$, yielding $520 \mathrm{~nm}$ and $1362 \mathrm{~nm}$, respectively.

Before the reaction, high resolution optical images of the compacted porous medium or the fractured medium were taken and the images were stitched for visualization of the porous media structure (see fig. 2 a and b). In each experiment, two regions of interest (e.g. compacted regions or regions along a fracture) were selected and the mineralogical changes were monitored at regular time intervals using Raman spectroscopy, see fig. 2 c and d. In situ hyperspectral Raman images were recorded from an area of $60 \mu \mathrm{m} \times 50 \mu \mathrm{m}$ with a $260 \mathrm{~nm}$ step size (232 pixel $\times 192$ pixel per image) in $\mathrm{x}$ and $\mathrm{y}$ direction. The individual Raman spectra were collected during continuous $\mathrm{x}-\mathrm{y}$ stage movement. Raman intensities were recorded for $0.1 \mathrm{~s}$ in the wavenumber range from 300 to $1300 \mathrm{~cm}^{-1}$. During the Raman measurements, the adjustable laser power was set to $50 \mathrm{~mW}$ and the grating to 1800 groovesmin $^{-1}$ with a $500 \mathrm{~nm}$ entrance slit. The total exposure time was 1 hour and 43 minutes for a single image. The selected map area was a good compromise of the representative elementary volume $(<1 \%$ pore volume exchange) and acquisition time. At the end of the experiment, the mineral mappings of the reservoir and a depth scan along a $100 \mu \mathrm{m}$ line in the upstream region were carried out to visualize the minerals distribution in the cell. The step size were $2000 \mathrm{~nm}$ (475 pixel $\times 475$ pixel per image) in $\mathrm{x}$ and $\mathrm{y}$ direction, and $3840 \mathrm{~nm}$ step size in $\mathrm{x}$ and $384 \mathrm{~nm}$ in $\mathrm{z}$ direction (384 pixel $\times 42$ pixel per image), respectively. In addition, stacked Raman images were collected $25 \mu \mathrm{m} \times 50 \mu \mathrm{m}$ with a $260 \mathrm{~nm}$ step size (96 pixel $\times 192$ pixel per image) in $\mathrm{x}$ and $\mathrm{y}$ direction and over a depth of $13 \mu \mathrm{m}$ with a $1000 \mathrm{~nm}$ step size. These images were used to reconstruct the 3D geometry of the porous media skeleton.

Raman image stacks were visualized with Volume Viewer, an ImageJ plugin developed by Kai Uwe Barthel Internationale Medieninformatik, HTW Berlin (Germany), that shows stacks as slices, projections, or volumes within a 3D-space. We also used ImageJ 3D Viewer plugin 31. An image processing workflow was developed using ImageJ to measure the porosity and volume fraction of each mineral from the stacks. For that, each mineral phase was 


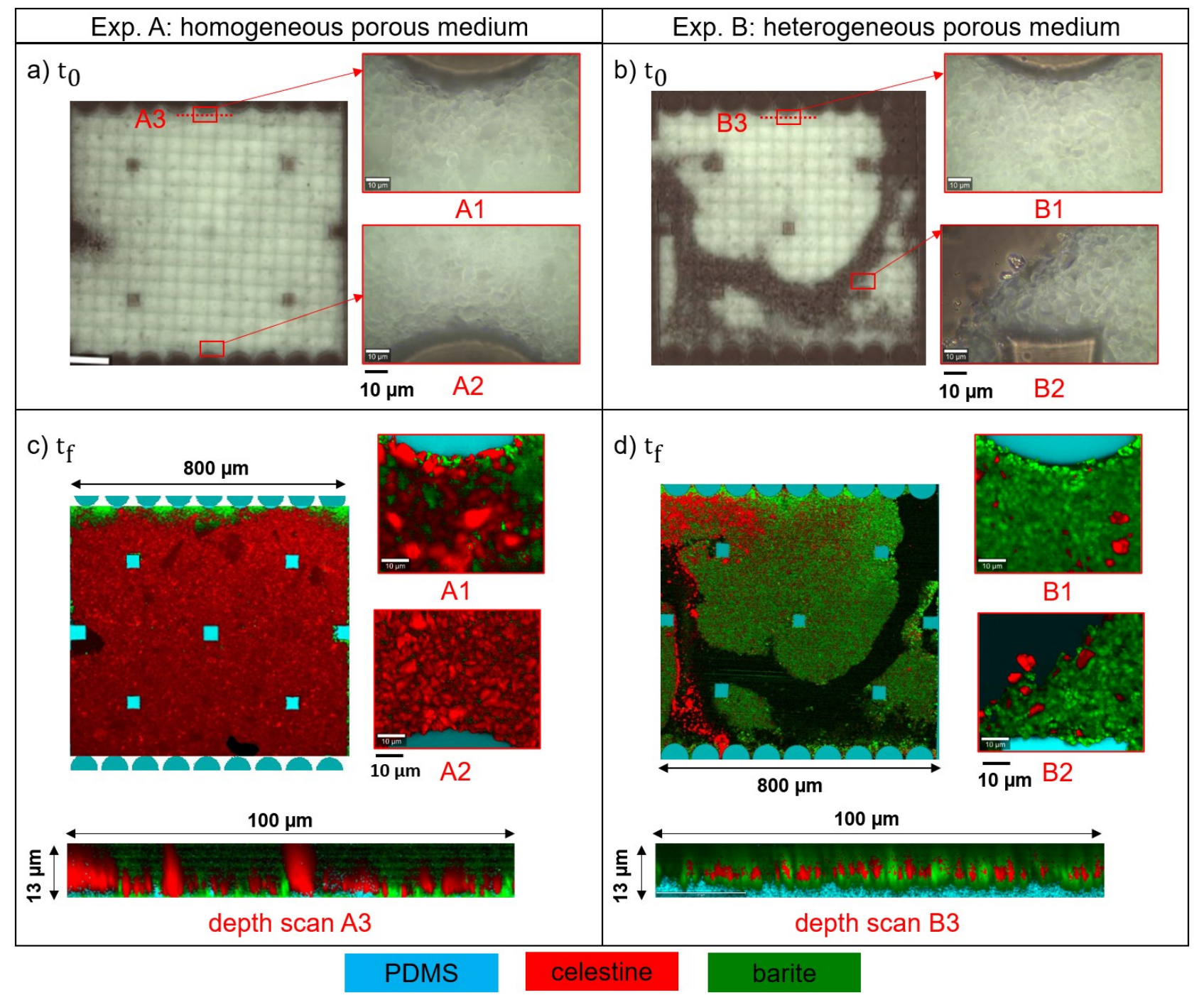

Fig. 2 a) Optical image of the reservoir filled with crystals constituting a homogeneous porous medium (experiment $A$ ) with a zoom on the monitored areas $A 1$ and $A 2, b)$ optical image of the reservoir filled with crystals constituting a heterogeneous (fracture occupying $30 \%$ of the domain) porous medium (experiment B), with a zoom on the monitored areas B1 and B2, c) Raman imaging of experiment A with a zoom on the monitored areas A1, A2 and depth scan A3 after 60 hours, d) Raman imaging of experiment B with a zoom on the monitored areas B1, B2, and depth scan areas B3 after 60 hours. The flow direction is from top to bottom 


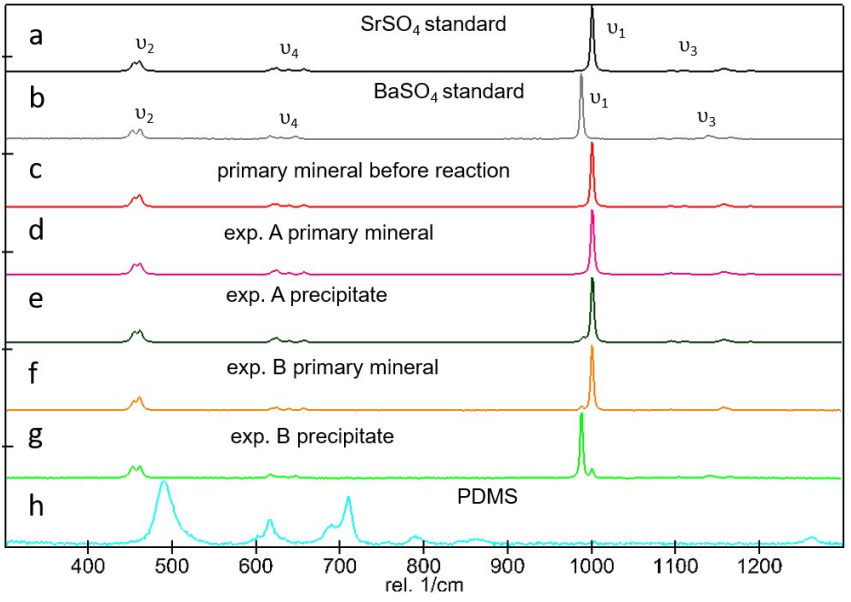

Fig. 3 Average Raman Spectra of a) $\mathrm{SrSO}_{4}$, b) $\mathrm{BaSO}_{4}$, c) unreacted celestine, d) primary celestine crystals in experiment $A, e)$ newly formed precipitates covering primary undissolved crystals in experiment $A, f$ ) undissolved primary minerals in experiment $B, g$ ) newly formed precipitate with relics of the undissolved crystals in experiment $B$ h) PDMS

converted to grayscale levels and segmented.

\section{Spectra analysis of the sulphate minerals and PDMS}

The Raman spectra of synthetic $\mathrm{BaSO}_{4}$ (99.99\% from Chempur), $\mathrm{SrSO}_{4}$ (99.99\% from Chempur) and the cured PDMS were collected for $0.4 \mathrm{~s}$ in the wavenumber range from 200 to $1400 \mathrm{~cm}^{-1}$. These measurements served as standards for further evaluation of our experimental data using the True Component Analysis module from Witec Control 5.6 Software. The free sulphate ions $\mathrm{SO}_{4}{ }^{2-}$ have a $T_{d}$ symmetry and therefore nine modes of vibrations ${ }^{32}$ represented as $A_{1}+E+2 F_{2}$ with $v_{1}\left(A_{1}\right)$ and $v_{3}\left(F_{2}\right)$ corresponding to the symmetric and the anti-symmetric stretching mode respectively, and $v_{2}(E)$ and $v_{4}\left(F_{2}\right)$ corresponding to the bending vibrations (Figure 3 ). The line positions depend on the nature of the cations, the temperature and pressure. The Raman spectra of the commercial $\mathrm{BaSO}_{4}$ and $\mathrm{SrSO}_{4}$ are shown in Fig 3 . Although, the spectra of $\mathrm{BaSO}_{4}$ and $\mathrm{SrSO}_{4}$ are rather similar, the very intense peak $\left(v_{1}\right)$ for barite and celestine are distinct at 989 and $1001 \mathrm{~cm}^{-1}$, respectively, and enables their identification. Under the given experimental conditions, barite and celestine can form solid solutions 33 which are usually characterised by a shift of their respective peaks, bringing them closer to each other and a broadening of their width. According to theoretical calculations (see supplemental information in Poonoosamy et al. ${ }^{13}$ ), solid solutions can be expected under our experimental conditions. However, the main focus of this study is to test the current setup for assessing the spatial/temporal mineralogical changes of the porous media; therefore solid solution composition is not addressed. The Raman spectrum of PDMS (Fig 3h) is different to that of the sulphate minerals and therefore does not interfere with the identification of the minerals.

\section{Numerical evaluation of velocity fields}

Numerical simulations were used to assess the local streamlines and velocity magnitudes in the microfluidic cell. This knowl- edge allows us to relate the different reaction rates observed in the porous matrix between experiments A and B to the transport mechanisms in the micromodel. Indeed, even though the fluid and crystal properties, as well as the injection rate, are the same for both cases, the spatial distribution of the crystals in the reservoir can change drastically the distribution of the local flow rates. Because of the large contrast of characteristic length scales between the fracture and the porous matrix formed by the assembly of the celestine crystals, a full Navier-Stokes solution in the entire domain is too computationally demanding and requires the exact knowledge of the three-dimensional structure of the porous regions. Instead, we used the micro-continuum Darcy-BrinkmanStokes approach developed by Soulaine and Tchelepi ${ }^{[35]}$ for which Stokes equations are solved within the fracture and the flow is described using Darcy's law in the matrix. Optical images of the microfluidic cell such as Fig. 7 are segmented into a solid phase (the white pillars), the void space that includes fractures and the spaces between the solid pillars (light grey) and the porous matrix (dark grey) and directly used to populate the micro-continuum model following the procedure introduced in Soulaine et al. 36 . The permeability and porosity of the celestine matrix are set to $2 \times 10^{-14} \mathrm{~m}^{2} 13$ and 0.865 (from Raman tomography measurement), respectively. In both cases, we use a constant injection velocity set to $9.25 \times 10^{-4} \mathrm{~m} / \mathrm{s}$ that corresponds to the mean velocity for the imposed flow rate in the experiments. The simulations are two-dimensional and the effects of the top and bottom plates of the micromodels are modelled adding a Hele-Shaw correction in the flow equations $24 \mid 37$. The micro-continuum model is implemented and solved using OpenFOAM, an open-source computational fluid dynamics platform that uses the finite-volume method to solve partial differential equations.

\section{Results and Discussion}

In this section, we evaluate the spatio-temporal mineralogical changes in experiment A and B and use the simulated velocity field to discuss the observed changes. Finally, we discuss uncertainties and optimization potential of Raman measurements.

\section{Mineral distribution in the system}

Mineral phases are identified by the characteristic positions and relative intensities of their fundamental Raman bands (Fig. 3). The Raman signature of the celestine before reaction is shown in (Fig. 35). Fig. 22 and d show the distribution of the remaining celestine (identified in red) and newly formed barite (identified in green) in experiments A and B. The average Raman spectra of the red regions are given in Fig. 3 A (experiment A) and Fig. 3 ; (experiment B), while that of green regions are given in Fig. 3 ? (experiment A) and Fig. 33 (experiment B).

In experiment $\mathrm{A}$, a $50 \mu \mathrm{m}$ wide precipitation front was observed at the upstream side of the reservoir, leaving the majority of celestine undissolved after the reaction time of 60 hours. The precipitation of barite in experiment $\mathrm{A}$, is characterised by a low intensity peak at $989 \mathrm{~cm}^{-1}$, as a shoulder to the high intensity celestine $v_{1}$ peak (Fig. 3 ). Barite also precipitated sparsely downstream in between the celestine grains (Fig. 25 area A2).Based on the 3D 
representation of experiment A (see supplementary material), we can infer that barite precipitated in the pore solution (homogeneous nucleation).

In experiment $\mathrm{B}$, the mineral distribution is heterogeneous (Fig. 2 2 d) with a higher barite content close to the fracture and higher content of celestine in the left side of the reservoir. The average Raman spectra of the green regions (Fig. $3 \mathrm{k}$ ) shows the signature of barite but also relics of the undissolved celestine crystals. The undissolved celestine crystals can be easily distinguished in the depth scans, where the Raman signal from celestine is seen. An average of the red regions identified as undissolved celestine shows minor contributions of barite (Fig. 33) suggesting barite precipitation on its surface (heterogeneous nucleation). Comparing the depth scan A3 and B3, the chemical reactions upstream (defined by celestine dissolution and consequential barite precipitation) appear more pronounced in experiment $B$ than in experiment A (see further assessment in Fig. 6).

Fig. 4 shows the mineralogical changes in regions B1 and B2 with time. The precipitation of barite starts on the step like features of the crushed celestine crystals (Fig. 4 at 10 hours), this is a common feature observed for barite epitaxial growth on celestine ${ }^{38}$ which is explained by the reduction of enthalpies due to the minimization of interfacial energies 39 . Barite precipitates on the surface of celestine and in between the celestine grains. From the temporal changes of Area B2, it appears that the reaction occurs in the compacted regions first rather than in regions directly in contact with the fracture, where crystals (see encircled crystal in Fig. (4) dissolve, shrink and become rounder.

\section{D representation of the porous structure}

Fig. 5 shows 3D representations of the porous micro-structure (Area A1 and B1 of experiment A and B, respectively) obtained from the stacked Raman images over a depth of $10 \mu \mathrm{m}$. The initial porosity was determined at 0.86 for area $\mathrm{A} 1$ in experiment $\mathrm{A}$ and 0.87 for area B1 for experiment B. After celestine dissolution and barite precipitation, the porosity increases to 0.91 for experiment $\mathrm{A}$ and decreases to 0.84 for experiment B. The volume fraction of minerals before and after reaction, measured for the images in Fig. 5, is shown in Fig. 6 The volume fraction of barite after the end of the experiment is 0.0017 and 0.16 in area $\mathrm{A} 2$ and $\mathrm{B} 2$, respectively, indicating a greater conversion of celestine to barite in experiment B. The replacement of celestine by barite is usually accompanied by a porosity decrease because of the larger molar volume of barite ${ }^{713}$. This decrease in porosity is indeed observed in experiment B, while in experiment A, a porosity increase in observed suggesting a faster dissolution that precipitation in during the time of the experiment. The 3D animated representation of the porous skeletons are presented in supplementary materials.

\section{Influence of the hydrodynamic heterogeneity on mineral re- activity}

The different barite distributions in experiments A and B are attributed to the difference in velocity fields in the two systems. In experiment $\mathrm{A}$, the velocity field is homogeneous with a mean velocity of $9.25 \times 10^{-4} \mathrm{~ms}^{-1}$ in the porous reservoir. This velocity is calculated from the injection flow rate and cross sectional area of the micromodel. In experiment B (Fig. 7 and 2 2 ), the velocity field is heterogeneous with the fastest flow path occurring along the fractures at $3.16 \times 10^{-3} \mathrm{~ms}^{-1}$ and the lowest flow rates observed in the compacted porous regions with an averaged value of $4.90 \times 10^{-5} \mathrm{~ms}^{-1}$. These results show that, for the same injection rates, the mean flow velocity through the celestine crystals exhibit orders of magnitude difference depending on whether the crystals are disposed uniformly in the reservoir or if they form a fractured porous medium. Indeed, we calculated that the flow rate through the compacted celestine crystals about a factor of 19 smaller in the heterogeneous case (experiment $\mathrm{B}$ ) than in the homogeneous case (experiment A). The Peclet numbers (Pe, defined as the ratio of advective and diffusive transport rates) in the compacted regions were calculated at 4.63 and 0.25 considering a characteristic length $5 \mu \mathrm{m}$ (mean pore size) for experiment A and experiment B, respectively. Therefore, the transport in the porous medium is advection-dominated in experiment $\mathrm{A}$ and diffusion-dominated in experiment $\mathrm{B}$. The observed higher volume of barite that precipitated in experiment B (in Area B1) compared to experiment A (in Area A1) can be explained by the lower velocities, lower Peclet number, thus by higher residence time that prevails in experiment B. Despite the same saturation index (logarithm of the ratio of activity of aqueous components over solubility product) in both experiments, barite precipitates in the pore space in experiment $A$ and on the surface of the celestine (in the compacted porous regions) in experiment $\mathrm{B}$. The saturation index that prevails in the system as the $1 \mathrm{mM} \mathrm{BaCl}_{2}$ reaches the celestine crystals is 3.35 , whereby heterogeneous nucleation should be favored over homogeneous nucleation (see Fig. 14 in Poonoosamy et al. $\frac{13}{13}$ ). However, it seems that the higher flow rates in experiment $\mathrm{A}$ compared to the flow rates in the porous region in experiment $B$ hinder the formation of barite clusters on the surface of celestine but add a mixing effect in the pore solution, which could favor homogeneous nucleation (mixing induced precipitation in porous media ${ }^{5}$ ).

Experiment $\mathrm{A}$ is also characterised by a sharp precipitation front. The rational could be that aqueous barium in the pore solution drops to the solubility limit of barite and consequently there is not enough barium in solution for further precipitation downstream. This is a phenomena that was observed in Poonoosamy et al.13. However, this is not the case here, as the number of moles of barium injected $1.8 \times 10^{-5} \mathrm{~mol}$ is higher than the amount of celestine $3 \times 10^{-12} \mathrm{~mol}$ present in the reactor. Therefore, it is most likely that the precipitation of barite downstream is kinetically hindered. Indeed as the pore solution gets depleted in aqueous barium, despite supersaturation, the energy barrier to nucleate further downstream might be too important to be overcome in the given short residence time (i.e. induction time for barite nucleation is much higher than the residence time). Homogeneous nucleation rate of barite drops abruptly to zero at saturation index of 3 (Fig. 14 in $\frac{13}{3}$ ). This is also in agreement with recent work on barite whereby authors reported that nucleation of barite require high supersaturation levels ${ }^{40}$ and delayed nucleation in confined space $^{21 / 38 / 41 / 42}$.

In experiment $\mathrm{B}$, the mineral transformation occurs in regions 
Area B1

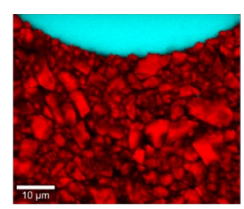

0

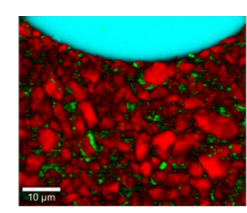

10

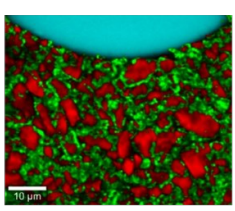

24

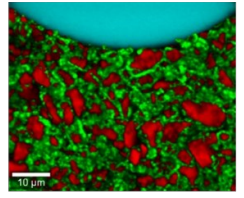

30

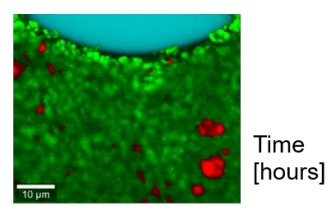

60

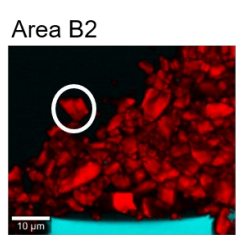

0

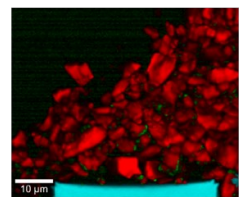

7

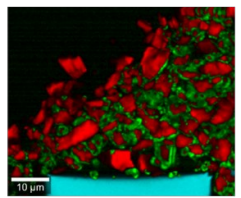

25

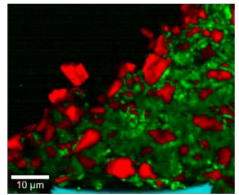

31

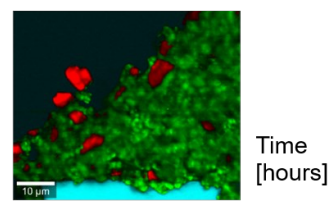

58

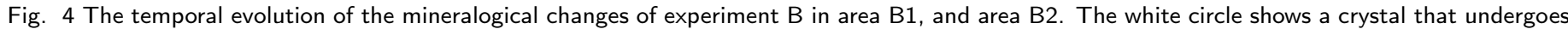
dissolution with time

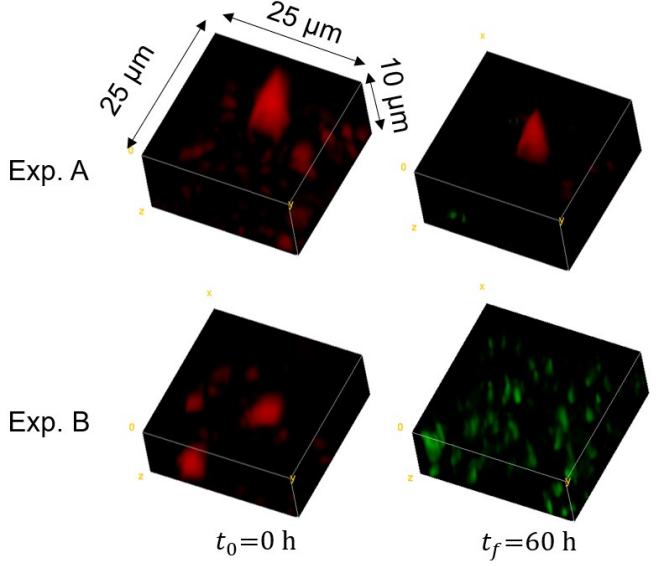

Fig. 5 The temporal evolution of the pore architecture in experiment $A$ and $\mathrm{B}$.

close to the main flow path (the fracture) with the left side of the reservoir without barite precipitation. In the regions close to the fracture, there is a continuous exchange between the pore solution and the fluid in the fracture, resulting in an increase in celestine dissolution and barite precipitation. The presence of a fracture also gives rise to local heterogeneity in the chemical reactions. This is emphasized in Fig. 4, where the temporal distribution of the minerals in area B1 and B2 is shown. A higher amount of barite precipitates on the compacted celestine crystals while the crystals along the fractures (Fig. 4 encircled crystal) seem to undergo dissolution. In the compacted regions, the flow velocities are lower increasing the residence time and therefore giving time for the concentration of $\mathrm{Ba}^{2+}$ and $\mathrm{SO}_{4}{ }^{2-}$ to increase in the pore solution and barite to precipitate. The constantly renewed solution in the fracture, is undersaturated with respect to strontium sulphate, driving the dissolution of celestine. Besides, due to relatively high velocities along the fracture (short transport time compared to induction time for barite nucleation); it is unlikely that barite nucleates on the surface of celestine directly adjacent

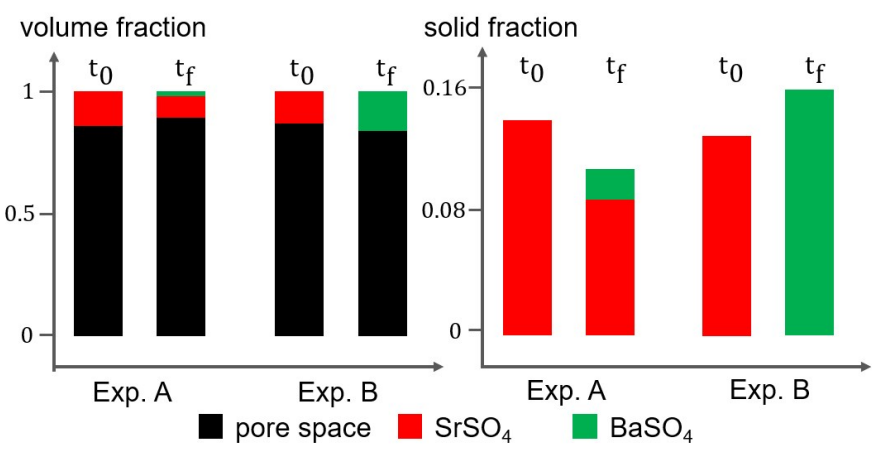

Fig. 6 evolution with time of volume fraction of celestine (red), barite (green) and pore space (black) in experiment A and B, in area A1 and B1 respectively

to the fracture. It is clear that the different transport velocities in both experiments affect the precipitation mechanisms in the porous media; and this will be further explored in future work.

\section{Uncertainties and optimization potential of Raman measure- ments}

In our study, a laser power of $50 \mathrm{~mW}$ was chosen, since such a laser power provides an excellent signal to noise ratio. However, we estimated that successive mapping is likely to increase the amount of dissolved celestine by less than $3 \%$ for the derived temporal temperature increase of about $7 \mathrm{C}$, compared to isothermal conditions (see Supplementary Material for details). To mitigate this effect for the given example (celestine to barite transformation), the laser power could be reduced to $30 \mathrm{~mW}$, as a clear distinction between celestine and barite can be made due to the high intensity of the $v_{1}$ bands. In addition, the mapping time can also be decreased by considering a step size of $500 \mathrm{~nm}$ instead of $260 \mathrm{~nm}$. Such optimization of the Raman measurements should be considered in the future to reduce or avoid potentially perturbing effects of laser induced heat on the experiments and the studied processes, such as increased mineral dissolution or faster 
a)

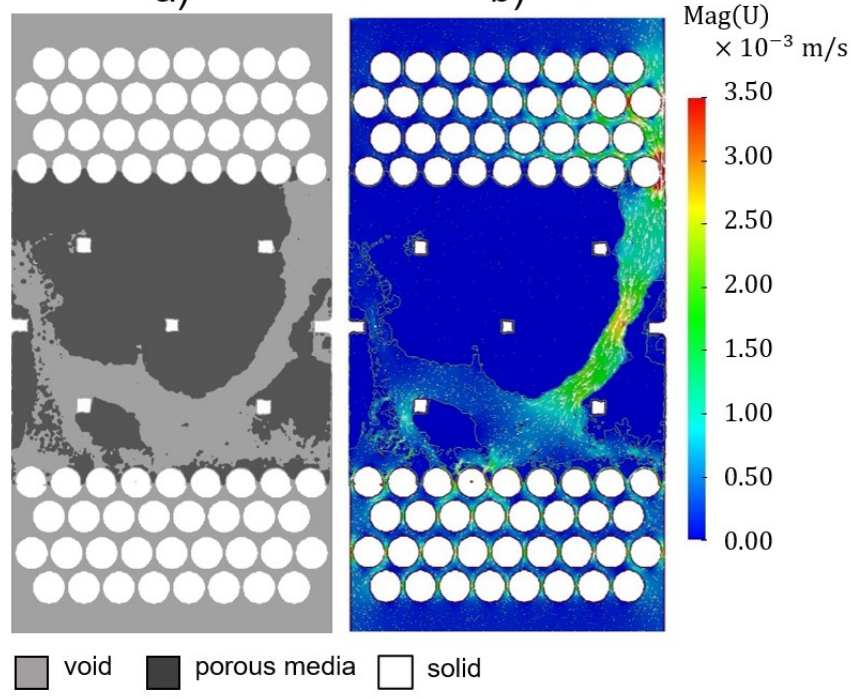

Fig. 7 a) 2D representation of the domains of experiment $B$ implemented in the numerical simulations $b$ ) associated velocity fields computed by the micro-continuum model.

reaction kinetics.

\section{Conclusions}

We developed and established a new flow-through microfluidic reactor coupled with high-resolution imaging that enables in situ and non destructive 3D assessment of mineralogical and microstructural changes with full spatio-temporal resolution on the grain scale. The micro-reactor consists of compacted reactive grains seeded in a reservoir within the microfluidic chip. Various degrees of heterogeneities can be considered ranging from uniform distribution of the grains to fractured porous media. In previous studies using macroscopic flow-through reactors to investigate the impact of supersaturation on the barite overgrowth on celestine, the ongoing dissolution and precipitation processes as well as the porosity evolution were inferred from post experimental destructive investigation. In comparison, this methodology allows a systematic study of the chemical and porosity evolution of the system at the pore-scale. In comparison, this methodology allows a systematic study of the chemical and porosity evolution of the system at the pore-scale. The presented micronized flow-through reactor monitored by non-invasive imaging Raman spectroscopy is a promising tool in capturing local processes for the interpretation of coupled chemical and transport processes observed at the macro-scale. In particular, our methodology allows the investigation of reactive transport processes in fractured porous media in well-controlled environments. The current setup can be extended to other chemical systems (e.g. calcite dissolution followed by gypsum precipitation, calcite by fluorite; gypsum by barite or celestine) for rationalizing coupled chemical processes and effect of different transport regimes (in terms of Peclet numbers and/or Damköhler numbers), on the mineral reactivity in (fractured) porous media. In this work, we have shown that it was possible to micronize conventional flow-through reactors to assess mineralogical changes at the pore scale, such concept can also be applied to micronize conventional diffusion cells such as those used, e.g.Chagneau et al. $\frac{8}{8}$ or Rajyaguru et al. 9 . Our methodological protocol is therefore a versatile tool in support of further developments in reactive transport modelling for assessing mineralogical changes and consequential porosity changes of porous media. Indeed, as reported in a recent review 10 , reactive transport models rely on the use of empirical relationships to predict the system evolution in terms of mineralogical changes and transport properties. The heterogeneity in porous media likely controls the mass fluxes and residence time in the reactive media and therefore are known to control the effective rates of mineral dissolution by reducing effective mineral surface areas physically (e.g. in fractures, or at partial saturation) and chemically 43.46. Moreover, the reactive surface area of minerals constituting the porous media is not directly experimentally accessible and is often used as a fitting parameter in reactive transport simulations 47 . In a future work, the Raman images of the evolving crystals can be used to evaluate the geometry and size of the crystals with time leading to calculation of dissolution rates. Moreover, pore-scale images can be used in pore-scale modelling. In fact, our in-situ 3D Raman reconstruction of the pore architecture along with advanced pore-scale modelling 14 will provide a better assessment of the transport properties (e.g. permeability, dispersion tensor) as well as the accessible reactive surface area and reaction rates for describing mineral precipitation/dissolution in porous media.

\section{Conflicts of interest}

There are no conflicts to declare.

\section{Acknowledgements}

The research leading to these results has received funding from the German Federal Ministry of Education and Research (BMBF, grant agreement 02NUK053A) and from the Initiative and Networking Fund of the Helmholtz Association (HGF grant SO-093) within the iCross project. This work has received support from the French Agency for Research (Agence Nationale de la Recherche, ANR) through the Equipex Planex ANR-11-EQPX-36, the labex Voltaire ANR-10-LABX-100-01, the grant CATCH ANR-18-CE050035, and through the FraMatI project under contract ANR-19CE05-0002. This project has received funding from the European Union's Horizon 2020 research and innovation programme under grant agreement No 847593. JP and SR would like to thank the DAAD and PROCOPE (Partenariat Hubert Curien) for their grant that enable the scholar exchange of scientists. This work was conducted with the technical support of Katherina Damen (IEK-6, FZJ). Last but not the least, JP would like to thank Guillermo Beltramo (ICS-7, FZJ) for his guidance in the selection of the Raman Microscope used in this work as well as Dietrich Kohlheyer (IBG$1, \mathrm{FZJ}$ ) for his guidance in setting up a microfluidic laboratory at IEK-6, FZJ.

\section{Contribution of authors}

JP designed the micromodel. JP and SR designed and conducted the experiments and processed the experimental results. CS conducted the modelling. JP, SR and CS discussed, interpreted the 
results and wrote the paper. $A B$ fabricated the silicon wafer. GD and DB applied for funding (HGF, BMBF). All authors revised the manuscript.

\section{Notes and references}

1 C. I. Steefel, C. A. J. Appelo, B. Arora, D. Jacques, T. Kalbacher, O. Kolditz, V. Lagneau, P. C. Lichtner, K. U. Mayer, J. C. L. Meeussen, S. Molins, D. Moulton, H. Shao, J. Simunek, N. Spycher, S. B. Yabusaki and G. T. Yeh, Computational Geosciences, 2015, 19, 445-478.

2 S. Molins and P. Knabner, Reviews in Mineralogy and Geochemistry, 2019, 85, 27-48.

3 J. Poonoosamy, C. Wanner, P. Alt Epping, J. F. Águila, J. Samper, L. Montenegro, M. Xie, D. Su, K. U. Mayer, U. Mäder, L. R. Van Loon and G. Kosakowski, Computational Geosciences, 2018, 1-22.

4 A. Idiart, M. Laviña, G. Kosakowski, B. Cochepin, J. C. Meeussen, J. Samper, A. Mon, V. Montoya, I. Munier, J. Poonoosamy, L. Montenegro, G. Deissmann, S. Rohmen, L. H. Damiani, E. Coene and A. Nieves, Applied Geochemistry, 2020, 115, 104562.

5 A. Tartakovsky, G. Redden, P. Lichtner, T. Scheibe and P. Meakin, Water Resources Research, 2008, 44, W06S04.

6 G. Katz, B. Berkowitz, A. Guadagnini and M. Saaltink, Journal of Contaminant Hydrology, 2011, 120-121, 27-44.

7 J. Poonoosamy, G. Kosakowski, L. Van Loon and U. Mäder, Journal of Contaminant Hydrology, 2015, 177-178, 1-17.

8 A. Chagneau, F. Claret, F. Enzmann, M. Kersten, S. Heck, B. Madé and T. Schäfer, Geochemical Transactions, 2015, 16, 13.

9 A. Rajyaguru, E. L'Hôpital, S. Savoye, C. Wittebroodt, O. Bildstein, P. Arnoux, V. Detilleux, I. Fatnassi, P. Gouze and V. Lagneau, Chemical Geology, 2019, 503, 29-39.

10 N. Seigneur, K. U. Mayer and C. I. Steefel, Reviews in Mineralogy and Geochemistry, 2019, 85, 197-238.

11 S. Churakov and N. Prasianakis, American Journal of Science, 2018, 318, 921-948.

12 C. Noiriel, P. Gouze and D. Bernard, Geophysical Research Letters, 2004, 31, 1-4.

13 J. Poonoosamy, M. Klinkenberg, G. Deissmann, F. Brandt, D. Bosbach, U. Mader and G. Kosakowski, Geochimica et Cosmochimica Acta, 2020, 43-60.

14 N. Prasianakis, M. Gatschet, A. Abbasi and S. Churakov, Geofluids, 2018, 2018, 9260603.

15 C. Soulaine, S. Roman, A. Kovscek and H. A. Tchelepi, J. Fluid Mech., 2017, 827, 457-483.

16 C. Soulaine, S. Roman, A. Kovscek and H. A. Tchelepi, Journal of Fluid Mechanics, 2018, 855, 616-645.

17 S. Molins, C. Soulaine, N. Prasianakis, A. Abbasi, P. Poncet, A. Ladd, V. Starchenko, S. Roman, D. Trebotich, H. Tchelepi and C. Steefel, Computational Geosciences, 2020, 1-34.

18 J. Poonoosamy, S. Haber-Pohlmeier, H. Deng, G. Deissmann, M. Klinkenberg, B. Gizatullin, S. Stapf, F. Brandt, D. Bosbach and A. Pohlmeier, Minerals, 2020, 10, 226.
19 J. Kulenkampff, M. Stoll, M. Gründig, A. Mansel, J. LippmannPipke and M. Kersten, Scientific Reports, 2018, 8, 7091.

20 A. Shafizadeh, T. Gimmi, L. Van Loon, A. Kaestner, E. Lehmann, U. Maeder and S. Churakov, author, 2015, pp. 516-523.

21 N. I. Prasianakis, E. Curti, G. Kosakowski, J. Poonoosamy and S. V. Churakov, Scientific Reports, 2017, 7, 13765.

22 C. Noiriel, P. Gouze and B. Madé, Journal of Hydrology, 2013, 486, 211-223.

23 S. Molins, D. Trebotich, L. Yang, J. B. Ajo-Franklin, T. J. Ligocki, C. Shen and C. I. Steefel, Environmental Science \& Technology, 2014, 48, 7453-7460.

24 S. Roman, C. Soulaine, M. A. AlSaud, A. Kovscek and H. Tchelepi, Adv. Water Resour., 2016, 95, 199-211.

25 W. Song, T. W. de Haas, H. Fadaei and D. Sinton, Lab Chip, 2014, 14, 4382-4390.

26 R. Singh, M. Sivaguru, G. A. Fried, B. W. Fouke, R. A. Sanford, M. Carrera and C. J. Werth, Journal of Contaminant Hydrology, 2017, 204, 28 - 39.

27 W. Hummel, U. Berner, E. Curti, F. Pearson and T. Thoenen, Radiochimica Acta, 2002, 90,

28 A. Grunberger, C. Probst, S. Helfrich, A. Nanda, B. Stute, W. Wiechert, E. von Lieres, K. Nöh, J. Frunzke and D. Kohlheyer, Cytometry Part A, 2015, 87, 1101-1115.

29 A. Burmeister, F. Hilgers, A. Langner, C. Westerwalbesloh, Y. Kerkhoff, N. Tenhaef, T. Drepper, D. Kohlheyer, E. von Lieres, S. Noack and A. Grunberger, Lab on a chip, 2019, 19, $98-110$.

30 D. Goosens, Sedimentology, 2008, 55, 65-96.

31 B. Schmid, J. Schindelin, A. Cardona, M. Longair and M. Heisenberg, BMC bioinformatics, 2010, 11, 274.

32 K. Ben Mabrouk, T. H. Kauffmann, H. Aroui and M. D. Fontana, Journal of Raman Spectroscopy, 2013, 44, 16031608.

33 M. Klinkenberg, J. Weber, J. Barthel, V. Vinograd, J. Poonoosamy, M. Kruth, D. Bosbach and F. Brandt, Chemical Geology, 2018, 497, 1-17.

34 F. Brandt, M. Klinkenberg, J. Poonoosamy, J. Weber and D. Bosbach, Minerals, 2018, 8, year.

35 C. Soulaine and H. A. Tchelepi, Transport In Porous Media, 2016, 113, 431-456.

36 C. Soulaine, F. Gjetvaj, C. Garing, S. Roman, A. Russian, P. Gouze and H. Tchelepi, Transport in Porous Media, 2016, 113, 227-243.

37 H. Lamb, Hydrodynamics, Cambridge, University Press, 3rd edn, 1906.

38 J. Poonoosamy, E. Curti, G. Kosakowski, D. Grolimund, L. Van Loon and U. Mäder, Geochimica et Cosmochimica Acta, 2016, 182, 131-144.

39 J. J. De Yoreo and P. G. Vekilov, Reviews in Mineralogy and Geochemistry, 2003, 54, 57-93.

40 J. Weber, J. Barthel, M. Klinkenberg, D. Bosbach, M. Kruth and F. Brandt, Chemical Geology, 2017, 466, 722-732.

41 M. Prieto, Mineralogical Magazine, 2014, 78, 1437-1447. 
42 J. Poonoosamy, C. Westerwalbesloh, G. Deissmann, M. Mahrous, E. Curti, S. Churakov, M. Klinkenberg, D. Kohlheyer, E. von Lieres, D. Bosbach and N. Prasianakis, Chemical Geology, 2019, 528, 119264.

43 H. Jung and A. Navarre-Sitchler, Geochimica et Cosmochimica Acta, 2018, 234, 70-83.

44 H. Deng, S. Molins, D. Trebotich, C. Steefel and D. DePaolo, Geochimica et Cosmochimica Acta, 2018, 239, 374-389.

45 H. Deng, C. Steefel, S. Molins and D. DePaolo, ACS Earth and Space Chemistry, 2018, 2, 112-124.

46 B. Berkowitz, I. Dror, S. Hansen and H. Scher, Reviews of Geophysics, 2016, 54, 930-986.

47 C. Noiriel, L. Luquot, B. Madé, L. Raimbault, P. Gouze and J. van der Lee, Chemical Geology, 2009, 265, 160-170. 